\title{
Outbreak of urogenital schistosomiasis in Corsica (France): an epidemiological case study
}

Jérôme Boissier, Sébastien Grech-Angelini, Bonnie L Webster, Jean-François Allienne, Tine Huyse, Santiago Mas-Coma, Eve Toulza, Hélène Barré-Cardi, David Rollinson, Julien Kincaid-Smith, Ana Oleaga, Richard Galinier, Joséphine Foata, Anne Rognon, Antoine Berry, Gabriel Mouahid, Rémy Henneron, Hélène Moné, Harold Noel, Guillaume Mitta

Université de Perpignan Via Domitia, IHPE UMR 5244, CNRS, IFREMER, Université de Montpellier, Perpignan, France (J Boissier PhD, J-F Allienne BSc, E Toulza PhD, J Kincaid-Smith MSc, R Galinier PhD, A Rognon MSc, G Mouahid PhD, H Moné PhD, G Mitta PhD)

INRA, Laboratoire de recherches sur le développement de l'élevage, Corte, France (S Grech-Angelini $\mathrm{MD})$

Department of Life Sciences, Parasites and Vectors Division, Natural History Museum, London, UK (B L Webster PhD, D Rollinson PhD)

London Centre for Neglected Tropical Disease Research, London, UK (D Rollinson, B L Webster)

Department of Biology, Royal Museum for Central Africa, Tervuren, Belgium and Laboratory of Biodiversity and Evolutionary Genomics, Biology, University of Leuven, Leuven, Belgium (T Huyse PhD)

Departamento de Parasitologia, Facultad de Farmacia, Universidad de Valencia, Burjassot, Valencia, Spain (S Mas-Coma PhD)

OCIC, ECOTER, Office de l'Environnement de la Corse, Corte, France (H Barré-Cardi PhD)

Unité de suivi entomologique et de politique de lutte anti vectorielle, Agence régionale de santé de Corse, Ajaccio, France (H Barré-Cardi)

Parasitology Laboratory, Instituto de Recursos Naturales y Agrobiología de Salamanca (IRNASA, CSIC), Salamanca, Spain (A Oleaga PhD)

Equipe parasites et écosystèmes méditerranéens, UMR 6134 CNRS SPE Science pour I'environnement, Université de Corse Pascal Paoli, Corte, France (J Foata PhD)

Service de Parasitologie-Mycologie, CHU Toulouse and Centre de Physiopathologie de Toulouse Purpan, INSERM U1043, CNRS UMR5282, Université de Toulouse, Toulouse, France (A Berry MD)

Hôpital Sainte Marguerite, Hopitaux Sud de Marseille, Marseille, France (R Henneron MD)

French Institute for Public Health Surveillance (Institut de Veille Sanitaire, InVS), Saint-Maurice, France (H Noel MD)

Corresponding author Dr Jérôme Boissier (boissier@univ-perp.fr) 


\section{Summary}

\section{Background}

Schistosomiasis is a snail-borne parasitic disease endemic in several tropical and subtropical countries. However, in the summer of 2013, an unexpected outbreak of urogenital schistosomiasis occurred in Corsica, with more than 120 local people or tourists infected. We used a multidisciplinary approach to investigate the epidemiology of urogenital schistosomiasis in Corsica, aiming to elucidate the origin of the outbreak.

\section{Methods}

We did parasitological and malacological surveys at nine potential sites of infection. With the snails found, we carried out snail-parasite compatibility experiments by exposing snails to schistosome larvae recovered from the urine of a locally infected Corsican patient. Genetic analysis of both mitochondrial (cox1) and nuclear (internal transcribed spacer) DNA data from the Schistosoma eggs or miracidia recovered from the infected patients was conducted to elucidate the epidemiology of this outbreak.

\section{Findings}

We identified two main infection foci along the Cavu River, with many Bulinus truncatus snails found in both locations. Of the 3544 snails recovered across all sites, none were naturally infected, but laboratory-based experimental infections confirmed their compatibility with the schistosomes isolated from patients. Molecular characterisation of 73 eggs or miracidia isolated from 12 patients showed infection with Schistosoma haematobium, $S$ haematobium-Schistosoma bovis hybrids, and $S$ bovis. Further sequence data analysis also showed that the Corsican schistosomes were closely related to those from Senegal in west Africa.

\section{Interpretation}

The freshwater swimming pools of the Cavu River harbour many $B$ truncatus snails, which are capable of transmitting $S$ haematobium-group schistosomes. Our molecular data suggest that the parasites were imported into Corsica by individuals infected in west Africa, specifi cally Senegal. Hybridisation between $S$ haematobium and the cattle schistosome $S$ bovis had a putative role in this outbreak, showing how easily and rapidly urogenital schistosomiasis can be introduced and spread into novel areas where Bulinus snails are endemic, and how hybridisation could increase the colonisation potential of schistosomes. Furthermore our results show the potential risk of schistosomiasis outbreaks in other European areas, warranting close monitoring and surveillance of all potential transmission foci. 


\section{RESEARCH IN CONTEST}

\section{Evidence before this study}

Reports of the emergence of vector-borne tropical diseases in European countries are scarce and mainly related to arthropod-borne diseases (eg, dengue and chikungunya). Human schistosomiasis, which is transmitted by freshwater snails, is regarded as a tropical disease found in developing countries, so the outbreak in southern Europe in 2013 was unexpected. We searched PubMed, Science Direct, and the WHO bibliographic databases for reports of human schistosomiasis in Europe, with no restrictions on date or language, using the terms "Schistosoma" and "Europe". Ten reports in English and Portuguese described a unique human outbreak of urogenital schistosomiasis in Portugal from 1920 to 1967. Morphological evidence suggested that the outbreak was due to infection with Schistosoma haematobium and experimental studies showed compatibility between the local strain of freshwater snail and several African strains of S haematobium. It was concluded that this outbreak was probably a result of the introduction of the parasite by people travelling between Angola, where schistosomiasis is endemic, and Portugal. However, at that time, no molecular tools were available to characterise the parasite or establish its origin. Subsequently, urogenital schistosomiasis was eliminated from Portugal in the early 1970s and has not been detected in Europe since. Since 2013, six reports have described an outbreak of urogenital schistosomiasis on the Mediterranean Island of Corsica, which has alerted the scientific community to the risk of urogenital schistosomiasis transmission in southern Europe. Additionally, we reported the first molecular description of the parasites from this outbreak, which we obtained from a single German patient. We showed that the patient was infected with not only $S$ haematobium, but also with $S$ haematobium-Schistosoma bovis hybrids.

\section{Added value of this study}

Our results can be used to create a map of transmission risk that could describe the location and abundance of compatible snail vectors, pinpoint the sources of infection, and aid future transmission monitoring and surveillance. Additional molecular data from parasites isolated from several infected tourists and Corsican locals, combined with existing data, suggests that the Corsican outbreak was the result of importation of the parasite from west Africa.

\section{Implications of all the available evidence}

Global changes, especially increases in mean temperatures and human movement, are expected to promote the emergence of tropical infectious diseases in higher latitudes than they are currently endemic in. Mosquito-borne diseases such as dengue, malaria, chikungunya, or Zika virus have captured the attention of the scientifi c community, but the risk of the emergence of schistosomiasis, a tropical snail-borne disease, has not been considered an imminent threat. Evidence shows that compatible snail vectors are endemic in several European countries, which raises the possibility of a new public health threat in Europe through the importation of schistosomes. Genetic data have proved fundamental to establish the origin of the Corsican outbreak and will be crucial for future epidemiological studies on schistosomiasis. 


\section{INTRODUCTION}

Increases in human travel, animal migration, and environmental changes are expected to promote the emergence of tropical infectious diseases in higher latitude environments. ${ }^{1}$ However, examples of the emergence of tropical infectious diseases in temperate areas remain scarce, with most reports being about diseases transmitted by arthropod vectors, including dengue, malaria, and chikungunya, which have been reported in southern parts of Europe including Italy and France. ${ }^{2-4}$ Aquatic freshwater snails are intermediate hosts (referred to as vectors in the case of vector-borne diseases) for several diseases caused by helminths, including the highly prevalent and debilitating neglected tropical disease schistosomiasis. This disease results from infection with parasitic worms of the Schistosoma genus and remains one of the world's most important neglected tropical diseases. Infection results from contact with fresh water that is contaminated with the free-swimming schistosome cercariae that are shed from infected snails.

Schistosoma haematobium causes human urogenital schistosomiasis and is transmitted by snails of the genus Bulinus. ${ }^{5}$ The geographical range of $S$ haematobium covers Africa, parts of the Middle East, Madagascar, and the Indian Ocean islands. More people are infected with $S$ haematobium than with all the other schistosome species combined. ${ }^{6}$ Of the more than 110 million cases of schistosomiasis in sub-Saharan Africa, 70 million are associated with haematuria, 18 million with bladder wall pathology, and 10 million with hydronephrosis leading to severe kidney disease ${ }^{7,8}$ and even bladder cancer. ${ }^{9} \mathrm{An}$ estimated 16 million women have female genital schistosomiasis, which causes complications related to fertility and transmission of HIV or other sexually transmitted infections. ${ }^{10} \mathrm{~S}$ haematobium eggs are voided in the urine of infected individuals and these eggs hatch when in contact with fresh water, releasing free-swimming miracidia that infect, develop, and replicate within suitable Bulinus snail hosts. ${ }^{11}$ Schistosoma bovis is a closely related sister species to $S$ haematobium that causes intestinal schistosomiasis in ruminants and is a major veterinary problem across Africa, but can also be found in European Mediterranean countries. ${ }^{12-14}$ Similar to $S$ haematobium, $S$ bovis is also transmitted by Bulinus snail species and both schistosome species inhabit sympatric geographical areas. This close phylogenetic association, combined with overlapping geographical distributions, enables hybridisation between $S$ haematobium and $S$ bovis, as has been reported in west African countries, namely Senegal. ${ }^{15,16}$ Hybridisation can alter disease epi demiology and enhance phenotypic characteristics that aff ect transmission and host compatibility. ${ }^{17}$ This hybridisation is especially important in relation to snail-parasite compatibility, whereby hybridisation can enable the use of a wider range of snail species and hosts ${ }^{16}$ and enhance the expansion potential of the disease. At the beginning of 2014 a cluster of urogenital schistosomiasis cases were diagnosed in patients in France (March, 2014) and Germany (January, 2014). ${ }^{18-20}$ The patients had never visited a schistosomiasis-endemic country, but all had spent their holidays in southern Corsica in August, 2013. Corsica, a French Mediterranean island, is very popular with tourists because of its natural beauty and Mediterranean climate. The freshwater intermediate host for schistosomes, Bulinus truncatus, is endemic in Corsica, 13 widely distributed throughout the perimeter of the island. ${ }^{21}$ The infected individuals had all been swimming in the Cavu River in the north of Porto Vecchio. After these fi rst cases were reported, the French Institute for Public Health Surveillance (Institut National de Veille Sanitaire [INVS]) and the European Centre for Disease Prevention and Control published a rapid risk assessment, which was followed by a large campaign between April, 2014, and April, 2015, to increase awareness of the risk of urogenital schistosomiasis infection in Corsica and the possible misdiagnosis of haematuria by European health practitioners. Subsequently, 124 more cases were reported in French nationals who visited Corsica and swam in the Cavu River in 2013. A case of acute schistosomiasis acquired in Corsica during the summer of 2015 has also been reported, suggesting that transmission is still persisting ${ }^{22}$ and poses a risk for further infections. Preliminary molecular analysis of schistosome eggs obtained from a German 
national who had the fi rst reported case of urogenital schistosomiasis acquired in Corsica showed the involvement of S haematobium and S bovis-S haematobium hybrids ${ }^{23}$ in the infection. In this study we used a multidisciplinary approach to investigate the epidemiology of urogenital schistosomiasis in Corsica, aiming to elucidate the origin of the outbreak.

\section{METHODS}

\section{Water contact site, livestock, and malacological surveys}

Nine potential sources of infection (water contact sites) were identifi ed from family holiday photographs and testimonials from local Corsican patients (figure 1). Cows and goats local to the Cavu River were tested by ELISA for schistosome infections, using methods described previously. ${ }^{24} \mathrm{After}$ the first cases of urogenital schistosomiasis acquired in Corsica were identified, snail surveys were done along the Cavu River, from May to September, 2014, aiming to find the sites of transmission. Surveys were done in a consistent manner at nine bathing sites that had been visited by at least one patient. Snails were collected with a sieve from all areas of the freshwater pools and aquatic plants at each site until no more could be readily found. The same approach was used at each site, and we compared random snail repartition between the different sites with the $\chi^{2}$ test. All morphologically identified Bulinus truncatus snails were tested for schistosome patent infection by cercarial shedding immediately and for several weeks after collection.

\section{Larval schistosome sampling}

After the publication of the rapid risk assessment and the campaign to increase awareness of the risk of urogenital schistosomiasis infection in Corsica, patients who were serologically diagnosed with urogenital schistosomiasis by physicians in Corsica and on the European continent were asked to provide urine samples to confirm diagnosis by parasitological analyses. The samples were examined microscopically for the presence of characteristic terminal spined schistosome eggs, and positive samples were stored at $4^{\circ} \mathrm{C}$ or in ethanol, then sent to the UMR5244 laboratory in Perpignan (France) for parasitological sampling. The samples were recorded as having come from either infected Corsican locals or tourists, but patients' details remained anonymous. No patients had ever been to a schistosomiasis-endemic area and all had been swimming in the Cavu River in the summer of 2013. This study was approved by the French Commission for Data Protection (Commission Nationale de I'Informatique et des Libertés) as part of the public health response. Data were processed anonymously and all schistosomiasis-positive patients were treated with praziquantel. Eggs were microscopically removed individually with an elongated Pasteur pipette from each urine sample, and when viable (ie, for eggs not stored in ethanol), attempts were made to hatch the eggs by placing them in fresh water. Any non-hatched eggs or free-swimming miracidia were individually captured using a pipette and prepared for DNA extraction.

\section{Molecular characterisation of schistosome miracidia or eggs}

DNA was extracted from individual miracidia or eggs $\mathrm{s}^{25}$ and the complete nuclear ribosomal DNA (rDNA) internal transcribed spacer (ITS) region and a partial fragment of the mitochondrial cytochrome oxidase subunit I (cox1) gene were amplifi ed by PCR and sequenced by a subcontractor (Genoscreen, Lille, France) for species characterisation (appendix $\mathrm{p} 1$ ). The sequences were assembled and manually edited with Sequencher software version 4.5. Sequence polymorphisms were checked and confi rmed by visualisation of the raw sequence chromatograms. Nuclear and mitochondrial profi les were assigned to each individual egg or miracidium analysed, as described previously ${ }^{15,16}$ (appendix $p 1$ ). The 
$S$ bovis or $S$ haematobium cox1 sequences obtained from the eggs or miracidia were grouped separately and then collapsed to group identical sequences of each species, creating unique haplotypes (appendix $\mathrm{p} 2$ ). The type of haplotype polymorphism and the numbers of individual samples representing each haplotype were recorded (tables 1-3). In our phylogenetic analysis, we included cox1 haplotype data from $S$ haematobium, $S$ bovis, and hybrids that were available from the National Center for Biotechnology Information database together with unpublished data from $S$ bovis from Spain and Africa (personal communication with $A O$ and BLW). We inferred the genealogical associations between haplotypes with PopART and we created minimum spanning networks to visualise the genealogical associations between the haplotypes. We inferred evolutionary associations between the haplotypes with Mega version 5.2.2, using the neighbour-joining, maximum parsimony and minimum evolution, maximum likelihood methods with the best fit evolution model (HKY $+G)$, which we established with the Akaike information criterion (AIC) implemented in jModelTest version 3.7.26 Analyses were subjected to 1000 bootstraps to infer the reliability of the branches, and topologies were rooted to a single sister species haplotype ( $S$ bovis for $S$ haematobium and $S$ haematobium for $S$ bovis).

\section{Host-parasite compatibility testing}

107 randomly selected $B$ truncatus snails ( $3-5 \mathrm{~mm}$ in size) collected in the Cavu River were individually exposed to one, two, or three miracidia that had been successfully hatched from the urine sample of a locally infected Corsican patient referred to as patient number 12 (table 1). Patient 12 was alone in excreting enough eggs for the snail exposure tests and technical constraints prevented us from using miracidia from any other patients. The number of exposed snails that became infected was recorded and eight laboratory hamsters were each exposed to pools of 400 cercariae. Animals were killed 12 weeks after parasite exposition in accordance with standard procedures. ${ }^{27}$ We used the same molecular methods as describeed earlier to molecularly characterise 20 female and 21 male worms recovered from these animals. All experiments on animals were done at the FR- 69 WHO collaborating centre laboratory under permit number A66040, received from both the French Ministry of Agriculture and Fishing and the French Ministry of National Education, Research and Technology (Décret \#87-848 du 19 Octobre 1987; authorisation number 007083). Animals were maintained and cared for in accordance with the ethical requirements of French Government.

\section{Role of the funding source}

The funder of the study had no role in study design, data collection, data analysis, data interpretation, or writing of the report. The corresponding author had full access to all the data in the study and had fi nal responsibility for the decision to submit for publication.

\section{RESULTS}

A total of 3544 B truncatus snails were collected from the nine sites on the Cavu River, but none produced schistosome cercariae. The first $B$ truncatus were found $800 \mathrm{~m}$ from the river mouth at site 2 (figure 1). The distribution of the snails was not random $\left(\chi^{2}=8812, p>0.0001\right)$, with most snails collected at sites 8 (1653 snails) and 9 (1650 snails).

Two families with one infected member each, one family with two infected members and one family with three infected members, all of which had been on holiday in Corsica in 2013 and we were able to be contacted, provided holiday photographs of their visits to the Cavu River. These together with testimonials from all 26 local Corsican patients enabled identifi cation of the potential freshwater 
sources of infection. Of the nine snail sampling sites, five had been visited by the infected patients (sites 5-9, appendix p 3). All of the personal photographs from the four tourist families were of site 9 (figure 1; appendix p 3), which was the most frequented site with 12 of the 26 local Corsican patients having only frequented this site. Similarly, four local patients only had water contact at site 8 . The ten remaining patients had visited several sites, mostly including sites 8 or 9 . These results suggest that sites 8 and 9 were the main sources of infection. Additionally, these suspected sites of infection presented the highest abundance of snails (fi gure 1). Three cows and 31 goats local to the Cavu River were serologically tested, but none were positive for schistosome infection.

A total of 137 eggs or miracidia were obtained from urine samples from 12 infected patients (six locals and six tourists). Complete sequence data were successfully obtained from 73 eggs or miracidia. The cox 1 sequences were identifi ed as being either $S$ haematobium or $S$ bovis (table 1 ). All ITS sequences except one, which was $S$ bovis, were $S$ haematobium and no double peaks were seen in the chromatograms at the four polymorphic positions between $S$ haematobium and $S$ bovis. ${ }^{15,16}$ Four patients produced only $S$ haematobium $-S$ bovis hybrids, four produced pure $S$ haematobium, three produced both hybrid and pure $S$ haematobium parasites, and one produced both an $S$ haematobium egg and a pure $S$ bovis egg (table 1 ).

We identified six unique $S$ haematobium cox 1 haplotypes (table 2 ) and eight unique $S$ bovis cox 1 haplotypes (table 3). 15 of the 73 samples had the $S$ haematobium haplotype that we termed ShD, which was identical to the haplotype that is the most dominant and common haplotype in Africa. ${ }^{28}$ The minimum spanning haplotype network (figure 2) shows the dominance of haplotype ShD as a central point from which the other five $S$ haematobium haplotypes branch off by one or two mutational steps. These mutations do not form a network and are non-synonymous, suggesting that they are random mutations that do not persist in the population.

The fi ve other haplotypes (ShA, ShB, ShC, ShE, ShF) cluster closely with the $S$ haematobium haplotypes from the African mainland (figure 2; appendix $\mathrm{p} 4$ ). For $S$ bovis, 23 of the samples formed a unique haplotype, $\mathrm{Sb2}$, and the minimum spanning haplotype network analysis shows the dominance of this haplotype as a central point from which all of the other haplotypes branch off by one or two steps. Like the $S$ haematobium haplotypes, the $S$ bovis haplotypes do not form a network and the mutations are non-synonymous, suggesting that they are random mutations that do not persist in the population (figure 3). The most dominant $S$ bovis haplotype, which we called $S b 2$, is identical to the $S$ bovis haplotype obtained from two humans infected with $S$ haematobium-S bovis hybrids in Senegal. ${ }^{15}$ The network analysis and phylogenetic analysis show the human $S$ bovis cox 1 haplotypes (Corsica and Senegal) clustering together and away from the animal $S$ bovis haplotypes (figures 3,4 ), providing strong evidence for a close genetic relationship between the schistosomes identifi ed in Corsica and those from west Africa, specifi cally Senegal.

17 of the $B$ truncatus snails from Corsica became infected after exposure to the schistosomes from Corsica (table 4). Cercariae resulting from these infections were able to successfully infect seven laboratory hamsters. We recovered 20 female and 21 male worms from the infected animals, which were molecularly characterised. All worms presented a hybrid genetic profi le consisting of $S$ bovis mitochondrial (mt)DNA cox1 (haplotype Sb2) and the $S$ haematobium nuclear rDNA ITS region.

\section{DISCUSSION}

Our study identifi ed two main infection foci along the Cavu River and showed that locally collected snails were compatible with the schistosomes from the infected patients. Molecular analyses allowed us to identify the hybrid status of the parasite and to infer the origin of the outbreak. Our results show the ease with which the schistosomes were able to invade and persist in a nonendemic area and the potential risk of dissemination of urogenital schisto somiasis to other southern European areas where 
suitable intermediate snail hosts are endemic, greatly facilitated by humans travelling from endemic areas to non-endemic areas.

During the 20th century, urogenital schistosomiasis became endemic in the southern Portuguese province of Algarve. ${ }^{29}$ The fi rst cases were recorded in 1921 and transmission is estimated to have ceased in the early 1970s. The origin of this outbreak is unknown, but it was postulated that the schistosomes were introduced by people travelling from either Morocco or a former Portuguese colony in Africa (eg, Angola, Mozambique, or Guinea Bissau). One important difference between transmission in Corsica and in Portugal is the intermediate snail host. Whereas $B$ truncatus is assumed to be the intermediate snail host in Corsica, in Portugal, Planorbarius metidjensis snails (not present in Corsica) were found to be naturally infected with schistosomes at the time of the outbreak and were therefore proposed as the intermediate host responsible for the schistosomiasis transmission. ${ }^{30}$ This finding was unexpected because $P$ metidjensis is not a typical host for $S$ haematobium and schistosomes are known to be highly specific for their intermediate snail hosts. One explanation for the involvement of $P$ metidjensis in the urogenital schistosomiasis outbreak in Portugal could have been the transmission of $S$ haematobium-S bovis hybrids instead of pure $S$ haematobium. Molecular tools for precise species identification were not available at that time so the infection was assumed to be due to infection with $S$ haematobium, although this could not be verified.

This hypothesis is supported by the fact that $S$ bovis has been identifi ed as using $P$ metidjensis as a natural intermediate snail host in the Iberian Peninsula ${ }^{31}$ and hybridisation between $S$ haematobium and $S$ bovis could make the resultant hybrid compatible with $P$ metidjensis. Schistosome hybridisation has been shown to widen the range of invertebrate hosts, with hybrid progeny inheriting the ability to develop in the specific intermediate snail hosts of both parental species. ${ }^{32}$ Further experimental crosses between $S$ haematobium and $S$ bovis are needed to assess the compatibility of the resulting progeny with $B$ truncatus, $P$ metidjensis, or both. Such experiments would allow the range of snail hosts of these hybrid schistosomes to be established and further clarify the risk of spread and introduction of these parasites into other European countries

Unfortunately we found no patent-infected snails in the Cavu River, which is not surprising because the prevalence of naturally infected snails is normally very low. ${ }^{33}$ However, we only screened for active patent infections, and additional methods to detect pre-patent infections, such as $\mathrm{PCR},{ }^{34}$ should be considered in future studies. We did compatibility experiments to investigate the role of the endemic $B$ truncatus in the Corsican outbreak. Our findings showed that there is high compatibility between the endemic snails and the schistosomes isolated from the infected patients, confirming their ability to be an intermediate snail host and supporting their role in transmission.

The molecular analysis of the Corsican schistosomes shows a close genetic relationship with schistosomes previously isolated from northern Senegal, suggesting a west African origin for the schistosomes in Corsica.

$S$ haematobium is endemic in 53 countries, ${ }^{35}$ and urogenital schistosomiasis is highly endemic across Senegal, with prevalence estimated around $25 \%$ of the total population, but ranging between $0 \%$ and $100 \%$ according to the region. ${ }^{36}$ Senegal was a French colony until 1958, but important ties remain between France and Senegal. Nationals travel freely between both countries and Senegal is a popular tourist destination for French nationals. French tourists can become infected in Senegal and infections are often reported in European travellers. ${ }^{37,38}$ Individuals might not know that they are infected and could introduce the parasite into places such as Corsica. Emigration from Senegal to Europe is frequent, with France remaining the most common destination. ${ }^{39}$ Senegalese nationals travelling legally to Corsica for summer work is common, creating an opportunity for the accidental importation of African schistosomes. The Cavu River, an ideal habitat for $B$ truncatus, is particularly attractive for recreational bathing or swimming, enabling the spread of urogenital schistosomiasis by infected people urinating in the freshwater pools. Corsica is visited by 3 million tourists every year, 
including 2.7 million in the high season between May and October. ${ }^{40}$ During the peak of the tourist season (from mid-July to mid-August) 3000-5000 people visit the Cavu River every day. These high visitor numbers, combined with the high abundance of suitable intermediate snail hosts and people travelling between Corsica and urogenital schistosomiasis-endemic areas, makes the Cavu River a highrisk area for the introduction and transmission of urogenital schistosomiasis

In a previous report, we showed that a 12 -year-old German boy who visited Corsica in $2013^{19}$ was exclusively excreting $S$ haematobium-S bovis hybrid schistosomes. ${ }^{23}$ Our present study includes data from 12 additional patients and depicts a more complex situation. These patients excreted both pure $S$ haematobium and S haematobium-S bovis hybrids, which is common in Senegal. ${ }^{15,16}$ Additionally, to our knowledge, we have detected the first pure $S$ bovis genotype from a human patient, suggesting that this patient was infected with pure $S$ bovis schistosomes. Since $S$ bovis is deemed to be a parasite of domestic livestock, this finding presents the first potential evidence for the zoonotic transmission of $S$ bovis. However, existing genotyping tools are limited in that we have used only two genes for hybrid identification and the nuclear genetic profiles can be affected by hybrid backcrossed generations, which would silence the genetic signal from one of the parental species. ${ }^{15}$ More genetic data are needed to fully elucidate whether this was a true case of zoonotic infection. Additionally, $S$ bovis is an intestinal schistosome, which runs counter to the notion that this is a pure zoonotic infection because these schistosomes were excreted in urine. Unlike the previous studies from Senegal, we did not see double chromatogram peaks in the nuclear ITS sequences at the polymorphic sites separating $S$ bovis and $S$ haematobium. This suggests that the Corsican hybrids are not fi rstgeneration hybrids resulting from $S$ haematobium and $S$ bovis schistosomes being dually transmitted in Corsica and mating within the infected patients, ${ }^{15}$ but are instead a result of the direct introduction of $S$ haematobium- $S$ bovis hybrids into Corsica alongside pure $S$ haematobium. This idea is further supported by the fact that we found no infected livestock in the area.

$B$ truncatus has a much wider distribution than its compatible schistosome species. These snails are endemic in southern Europe, including Spain, Italy, France, and Greece. Mean water temperatures are expected to increase in the south of Europe ${ }^{41}$ which will enhance the survival and fi tness of both the parasite and snail populations. Given the recent increase in migration from endemic areas across some of these regions, together with parasite genetic variants, the spread of parasite species becomes a real risk. This risk warrants further investigation, but also needs to be brought to the attention of European governments. Furthermore the findings from this study and all the other reports about urogenital schistosomiasis infection in Corsica, show how easily this form of schistosomiasis can spread even where good hygiene and sanitation practices are in place. Additionally the findings raise concerns as to how the transmission of urogenital schistosomiasis can be controlled, even in developed settings, which will hamper goals set to achieve elimination in endemic areas within the near future. ${ }^{42}$

\section{FUNDING}

WHO, ANSES, RICET, and the Ministry of Health and Consumption.

\section{CONTRIBUTORS}

$J B, B L W$, and TH wrote the manuscript. ET, GMo, HM, DR, SM-C, and GMi revised the manuscript. $J B, S G-A, J F, J K-S, A R, R G$, and HB-C did the malacological survey. SG-A collected animal blood samples. J-FA did the molecular analyses. AO did ELISA tests. JB, GMi, and RH questioned patients along the Cavu River. AB and HN supplied parasite samples. JB and AR did the experimental infections. BLW did the phylogenetic and phylogeographic analyses. 


\section{DECLARATION OF INTERESTS}

We declare no competing interests.

\section{ACKNOWLEDGMENTS}

This study was fi nancially supported by WHO, ANSES (agence nationale de sécurité sanitaire de I'alimentation, de l'environnement et du travail), and UPVD (University of Perpignan Via Domitia). Spanish collaboration was funded by Red de Investigación Cooperativa en Enfermedades Tropicales (RICET; number RD12/0018/0013 of the VI PN de I+D+I 2008-2011, ISCIII-Sub dirección General de redes temáticas de investigación cooperativa en salud [RETICS]) and the Ministry of Health and Consumption (Madrid, Spain). We thank Pierre Marty from CHU de Nice (Nice, France) and all members the Bilharziasis expert group of ANSES. We also thank Françoise Alluin and all the members of the 2A2B laboratory (Porto-Vecchio, France). 


\section{REFERENCES}

1 Bouzid M, Colón-González FJ, Lung T, Lake IR, Hunter PR. Climate change and the emergence of vector-borne diseases in Europe: case study of dengue fever. BMC Public Health 2014; 14: 781.

2 Schaffner F, Fontenille $D$, Mathis A. Autochthonous dengue emphasises the threat of arbovirosis in Europe. Lancet Infect Dis 2014; 14: 1044.

3 Rezza G, Nicoletti L, Angelini R, et al. Infection with chikungunya virus in Italy: an outbreak in a temperate region. Lancet 2007; 370: 1840-46.

4 Gould EA, Gallian P, De Lamballerie X, Charrel RN. First cases of autochthonous dengue fever and chikungunya fever in France: from bad dream to reality! Clin Microbiol Infect 2010; 16: 1702-04.

5 Rollinson D, Stothard JR, Southgate VR. Interactions between intermediate snail hosts of the genus Bulinus and schistosomes of the Schistosoma haematobium group. Parasitology 2001; 123 (suppl): S245-60.

6 Rollinson D. A wake up call for urinary schistosomiasis: reconciling research eff ort and public health importance. Parasitology 2009; 136: 1593-610.

7 King CH, Dickman K, Tisch DJ. Reassessment of the cost of chronic helmintic infection: a metaanalysis of disability-related outcomes in endemic schistosomiasis. Lancet 2005; 365: 1561-69.

8 van der Werf MJ, de Vlas SJ, Brooker S, et al. Quantifi cation of clinical morbidity associated with schistosome infection in sub-Saharan Africa. Acta Trop 2003; 86: 125-39.

9 Shiff C, Veltri R, Naples J, et al. Ultrasound verifi cation of bladder damage is associated with known biomarkers of bladder cancer in adults chronically infected with Schistosoma haematobium in Ghana. Trans R Soc Trop Med Hyg 2006; 100: 847-54.

10 Kjetland EF, Norseth HM, Taylor M, et al. Classifi cation of the lesions observed in female genital schistosomiasis. Int J Gynaecol Obstet 2014; 127: 227-28.

11 Rollinson D, Simpson AJG. The biology of Schistosomes. From genes to latrines. London: Academic Press, 1987.

12 De Bont J, Vercruysse J. The epidemiology and control of cattle schistosomiasis. Parasitol Today 1997; 13: 255-62.

13 Brumpt E. Cycle évolutif du Schistosoma bovis (Bilharzia crassa); infection spontanée de Bulinus contortus en Corse. CR Acad Sci III 1929; CLXXXXI: 879.

14 Grétillat $\mathrm{S}$. Epidémiologie de certaines aff ections à trématodes des animaux domestiques en Corse (Bilharziose bovine et distomatose bovine et ovine). Ann Parasitol Hum Comp 1963; 38: 471-81.

15 Webster BL, Diaw OT, Seye MM, Webster JP, Rollinson D. Introgressive hybridization of Schistosoma haematobium group species in Senegal: species barrier break down between ruminant and human schistosomes. PLoS Negl Trop Dis 2013; 7: e2110.

16 Huyse T, Webster BL, Geldof S, et al. Bidirectional introgressive hybridization between a cattle and human schistosome species. PLoS Pathog 2009; 5: e1000571.

17 Tchuem Tchuente LA, Southgate VR, Jourdane J, Webster BL, Vercruysse J. Schistosoma intercalatum: an endangered species in Cameroon? Trends Parasitol 2003; 19: 389-93.

18 Berry A, Moné $\mathrm{H}$, Iriart X, et al. Schistosomiasis haematobium, Corsica, France. Emerg Infect Dis 2014; 20: 1595-97. 19 Holtfreter MC, Moné H, Muller-Stover I, Mouahid G, Richter J. Schistosoma haematobium infections acquired in Corsica, France, August 2013. Euro Surveill 2014;

19: 20821.

20 Boissier J, Moné H, Mitta G, Bargues MD, Molyneux D, Mas-Coma S. Schistosomiasis reaches Europe. Lancet Infect Dis 2015; 15: 757-58.

21 Doby JM, Rault B, Deblock S, Chabaud A. Snails and bilharziasis in Corsica. Distribution, frequency and biology of Bulinus truncatus. Ann Parasitol Hum Comp 1966; 41: 337-49 (in French).

22 Berry A, Fillaux J, Martin-Blondel G, et al. Evidence for a permanent presence of schistosomiasis in Corsica, France, 2015. Euro Surveill 2016; 21: 3. 
23 Mone $\mathrm{H}$, Holtfreter $\mathrm{MC}$, Allienne JF, et al. Introgressive hybridizations of Schistosoma haematobium by Schistosoma bovis at the origin of the fi rst case report of schistosomiasis in Corsica (France, Europe). Parasitol Res 2015; 114: 4127-33.

24 de la Torre-Escudero E, Manzano-Roman R, Perez-Sanchez R, Barrera I, Siles-Lucas M, Oleaga A. Molecular cloning, characterization and diagnostic performance of the Schistosoma bovis 22.6 antigen. Vet Parasitol 2012; 190: 530-40.

25 Beltran S, Galinier R, Allienne JF, Boissier J. Cheap, rapid and effi cient DNA extraction method to perform multilocus microsatellite genotyping on all Schistosoma mansoni stages. Mem Instit Oswaldo Cruz 2008; 103: 501-03.

26 Posada D. jModelTest: phylogenetic model averaging. Mol Biol Evol 2008; 25: 1253-56.

27 Boissier J, Chlichlia K, Digon Y, Ruppel A, Moné H. Preliminary study on sex-related infl ammatory reactions in mice infected with Schistosoma mansoni. Parasitol Res 2003; 91: 144-50.

28 Webster BL, Emery AM, Webster JP, et al. Genetic diversity within Schistosoma haematobium: DNA barcoding reveals two distinct groups. PLoS Negl Trop Dis 2012; 6: e1882.

29 De Azevedo JF, Da Silva JB, Matos Coito A, Coelho MF, Colaco A. O foco Português de schistosomíase. An Inst Med Trop (Lisb) 1948; 5: 175-221.

30 Bettencourt A, Borges I. Le Planorbis metidjensis, hôte intermédiaire du Schistosoma haematobium au Portugal. Confi rmation expérimentale. C R Soc Biol 1922; 87: 1039-40.

31 Moné H, Mouahid G, Morand S. The distribution of Schistosoma bovis Sonsino, 1876 in relation to intermediate host mollusc-parasite relationships. Adv Parasitol 1999; 44: 99-138.

32 Webster BL, Southgate VR. Compatibility of Schistosoma haematobium, S. intercalatum and their hybrids with Bulinus truncatus and B. forskalii. Parasitology 2003; 127: 231-42.

33 Basch PF. Schistosomes. Development, reproduction, and host relations. New York: Oxford University Press, 1991.

34 Hamburger J, Hoff man O, Kariuki HC, et al. Large-scale, polymerase chain reaction-based surveillance of Schistosoma haematobium DNA in snails from transmission sites in coastal Kenya: a new tool for studying the dynamics of snail infection. Am J Trop Med Hyg 2004; 71: 765-73.

35 Chitsulo L, Engels D, Montresor A, Savioli L. The global status of schistosomiasis and its control. Acta Trop 2000; 77: 41-51.

36 Schur N, Hurlimann E, Garba A, et al. Geostatistical model-based estimates of Schistosomiasis prevalence among individuals aged $\leq 20$ years in West Africa. PLoS Negl Trop Dis 2011; 5: e1194.

37 Blach O, Rai B, Oates K, Franklin G, Bramwell S. An outbreak of schistosomiasis in travellers returning from endemic areas: the importance of rigorous tracing in peer groups exposed to risk of infection. J Public Health (Oxf) 2012; 34: 32-36.

38 Steiner F, Ignatius R, Friedrich-Jaenicke B, et al. Acute schistosomiasis in European students returning from fi eldwork at Lake Tanganyika, Tanzania. J Travel Med 2013; 20: 380-83.

39 Gerdes F. Focus Migration. Country profi le: Senegal, No 10, Nov 2007. Hamburg: Hamburg Institute of International Economics, 2007.

40 Agence du Tourisme de la Corse. Observation et stratégie touristiques 2013. http://www.bastia.aeroport.fr/Administration/ accueil/pdf/pdfdossp20121227141029.pdf (accessed May 2, 2016).

41 van Vliet MTH, Vodele S, Rubbelke D. Water constraints on European power supply under climate change: impacts on electricity prices. Environ Res Lett 2013; 8: 1-10.

42 Rollinson D, Knopp S, Levitz $\mathrm{S}$, et al. Time to set the agenda for schistosomiasis elimination. Ac ta Trop 2013; 128: 423-40. 


\section{Figure 1}

\section{Map of the Cavu River in the south of Corsica}

Malacological sampling was done at sites 1-9 along the Cavu River. $n / n=$ number of Bulinus truncatus snails collected at the site/number of infected patients that had unique water contact at the site

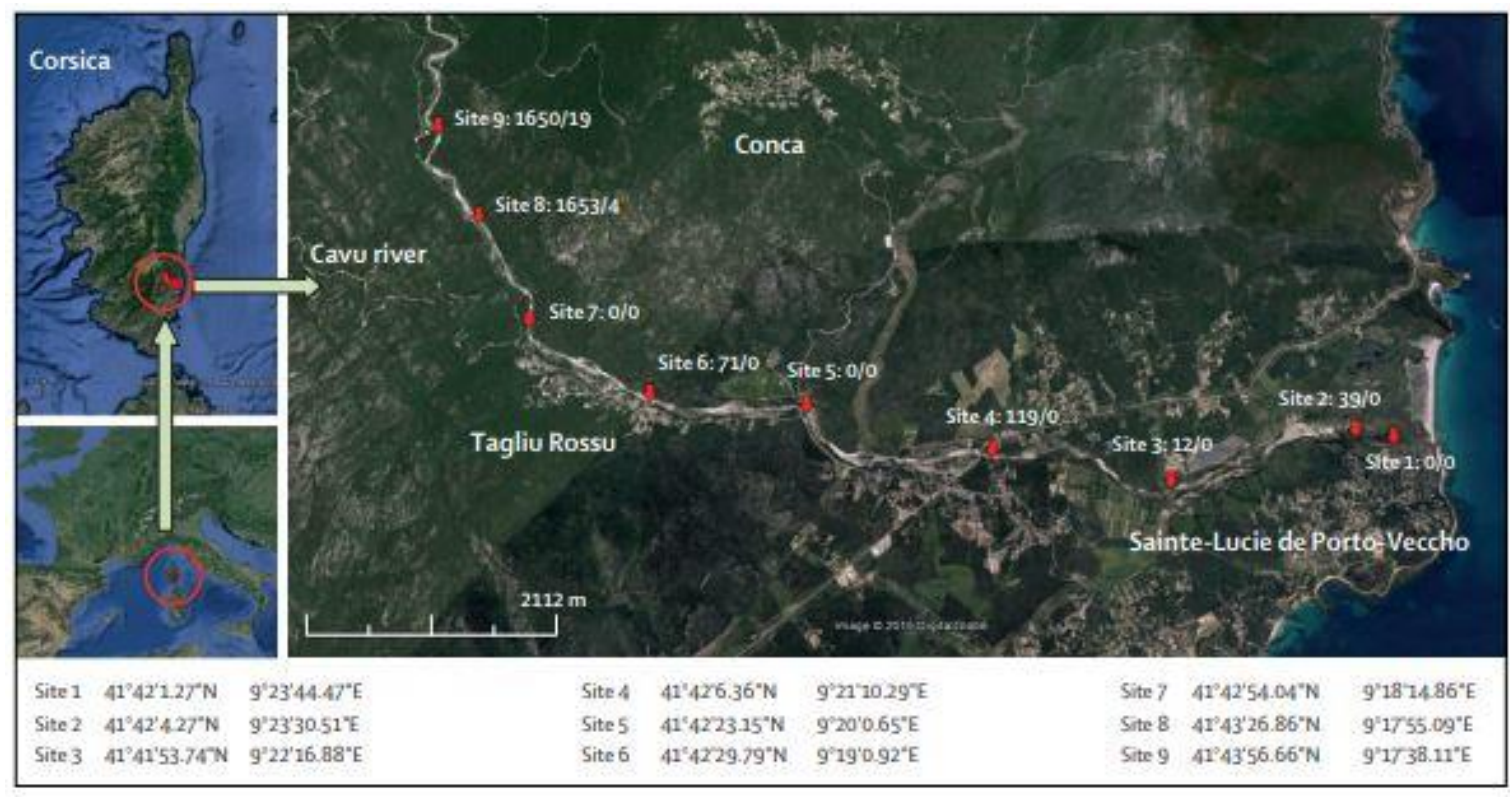




\section{Figure 2}

\section{Schistosoma haematobium mitochondrial DNA cox1 haplotype network}

Corsican S haematobium haplotypes are ShA, ShB, ShC, ShD, ShE, and ShF. H1 is a monophyletic group defined previously.28 Our data were compared with available $S$ haematobium cox 1 haplotype. cox1=mitochondrial cytochrome oxidase subunit I.

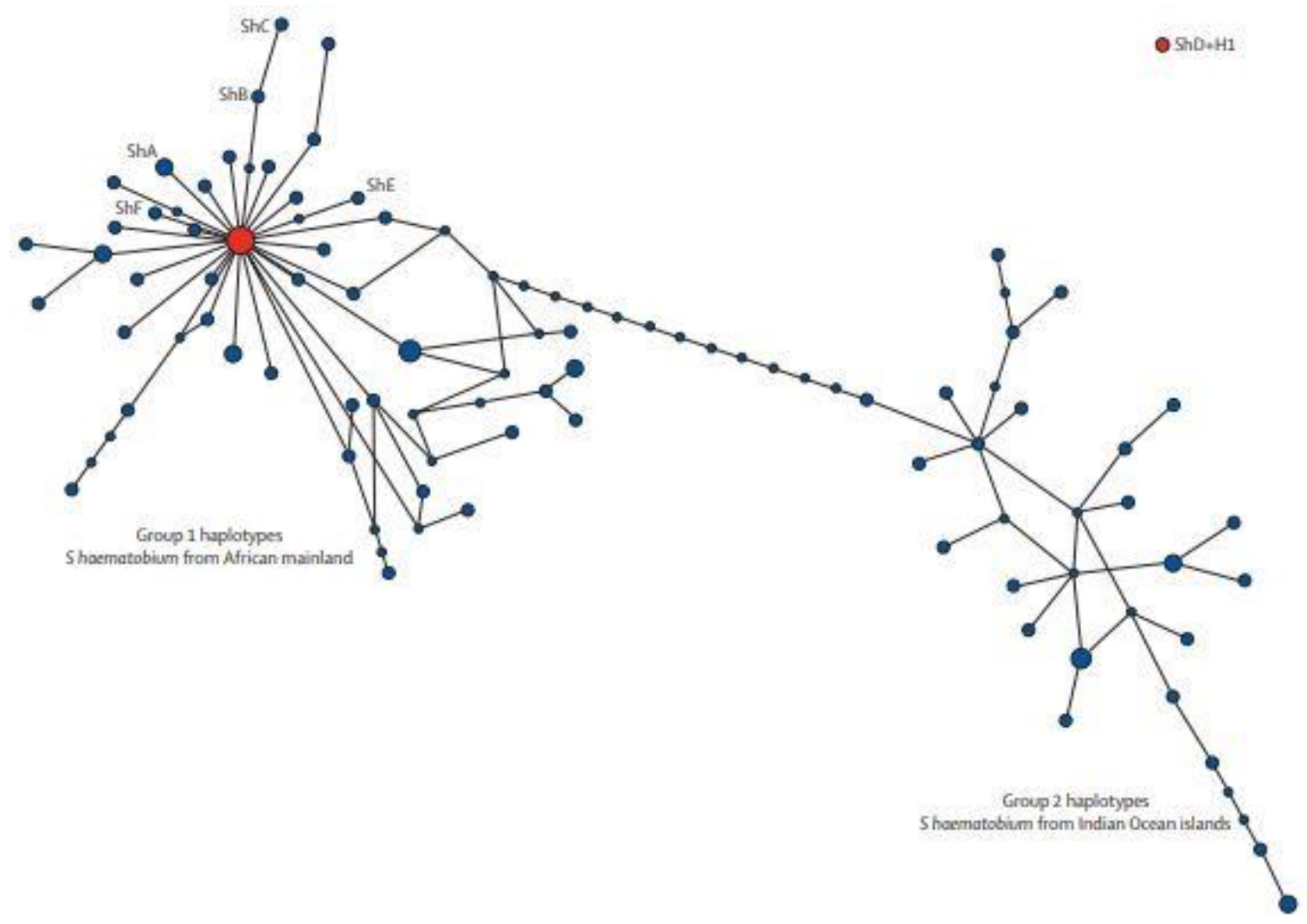




\section{Figure 3}

Schistosoma bovis mitochondrial DNA cox1 haplotype network

Our data were compared with available $S$ bovis cox1 haplotype data (appendix p 2). cox1=mitochondrial cytochrome oxidase subunit $\mathrm{I}$.

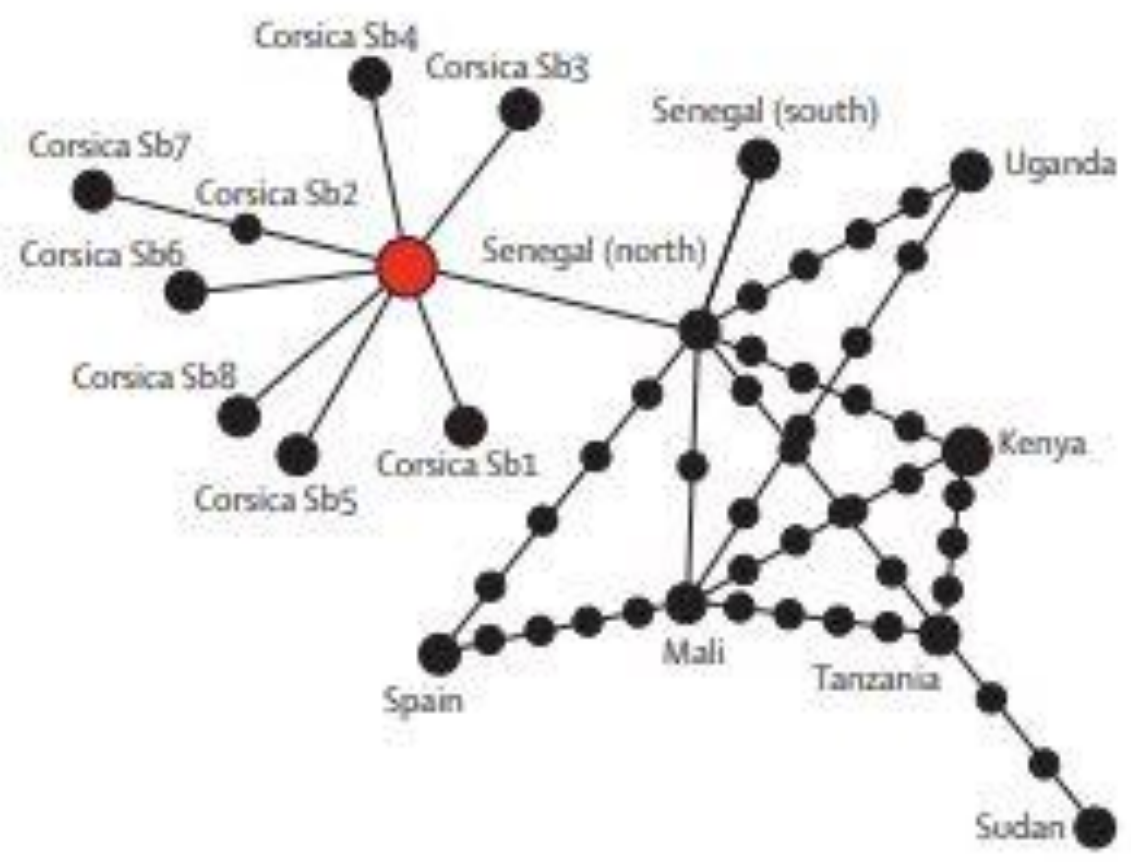




\section{Figure 4}

Phylogenetic tree of Schistosoma bovis mitochondrial DNA cox1 haplotypes

Our data were compared with available $S$ bovis cox1 haplotype data (appendix $p 2$ ). cox1=mitochondrial cytochrome oxidase subunit I.

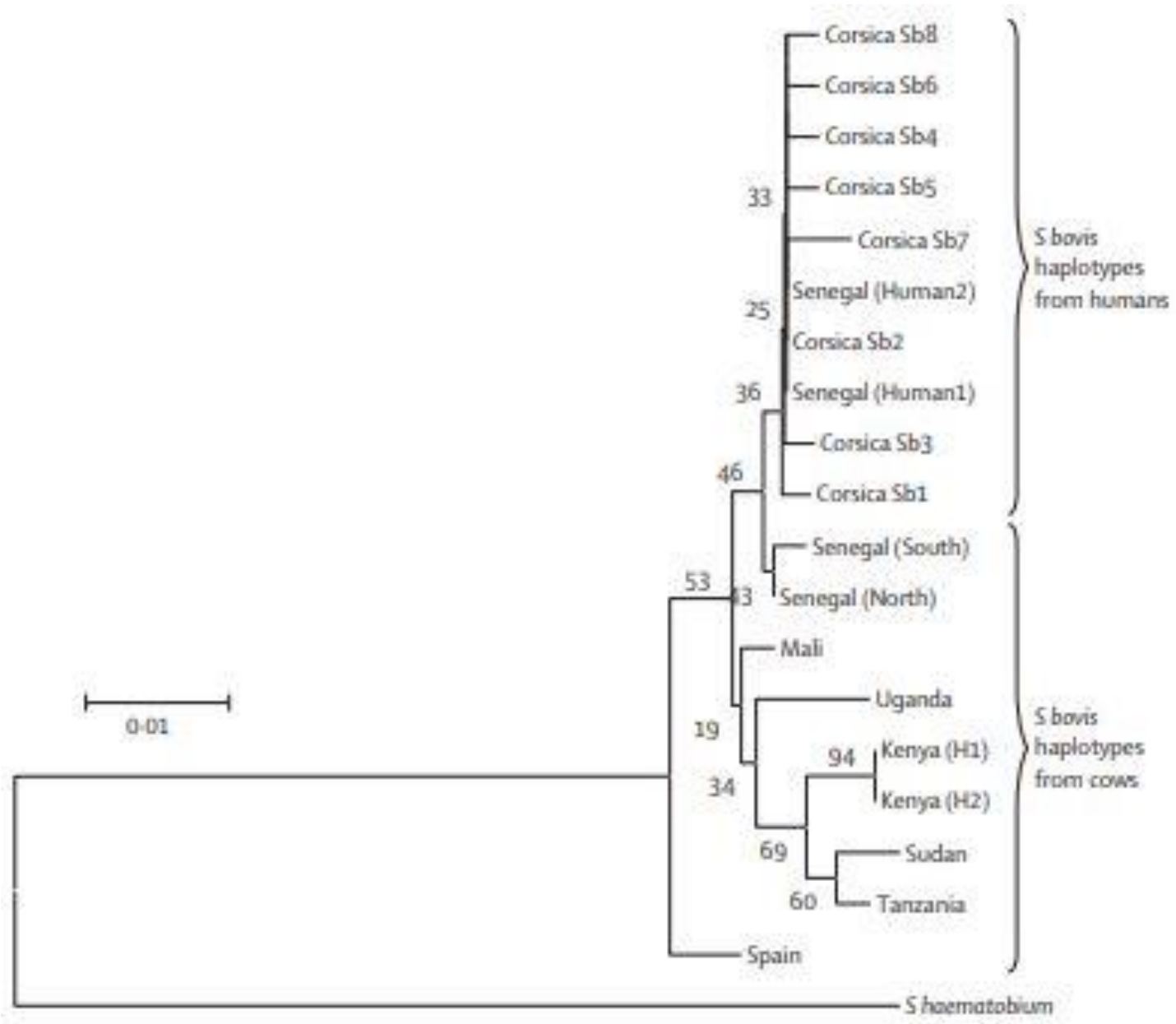




\section{Table 1}

Genetic profiles of individual eggs or miracidia

\begin{tabular}{|c|c|c|c|c|}
\hline & \multicolumn{2}{|c|}{ Sequence identification } & \multirow{2}{*}{$\begin{array}{l}\text { mtDNA } \\
\text { cox1 } \\
\text { haplotype } \\
\text { code* }\end{array}$} & \multirow{2}{*}{$\begin{array}{l}\text { Genetic } \\
\text { profilet }\end{array}$} \\
\hline & rDNA ITS & mtDNA cox 1 & & \\
\hline \multicolumn{5}{|l|}{ Patient 1} \\
\hline 3 eggs & Shoematobium & Sbovis & $\$ 52$ & Hybrid \\
\hline 1egg & Shaematobium & Shaernatobium & ShB & $5 h$ \\
\hline \multicolumn{5}{|l|}{ Patient 2} \\
\hline 1 egg & Shoematobium & Shaematobium & ShD & Sh \\
\hline 1 egg & Sbovis & Sbovis & $\$ b 2$ & $5 b$ \\
\hline \multicolumn{5}{|l|}{ Patient 3} \\
\hline 2 eggs & Shoematobium & Sbovis & $\mathrm{Sb} 2$ & Hybrid \\
\hline \multicolumn{5}{|l|}{ Patient 4} \\
\hline 7 miracidia & Shaematobium & Shaematobium & ShB & Sh \\
\hline 1 miracidium & Shoematobium & Shaematobium & Shc & Sh \\
\hline \multicolumn{5}{|c|}{ Patient $5 \ddagger$} \\
\hline 8 miracidia & Shaematobium & Shaematobium & ShA & $5 h$ \\
\hline \multicolumn{5}{|l|}{ Patient $6 \neq$} \\
\hline 8 miracidia & Shoematobium & Shaematobium & ShA & Sh \\
\hline \multicolumn{5}{|l|}{ Patient 7} \\
\hline 1 egg & Shoematobium & Sbovis & $\$ b 1$ & Hybrid \\
\hline 2 eggs & Shaematobium & Sbovis & $\mathrm{Sb} 2$ & Hybrid \\
\hline 1 egg & Shoematobium & Sbovis & $5 b_{3}$ & Hybrid \\
\hline \multicolumn{5}{|l|}{ Patient 8} \\
\hline 6 miracidia & Shoematobium & Shoematobium & ShD & Sh \\
\hline 1 miracidium & Shaematobium & Shaematobium & She & Sh \\
\hline 1 miracidium & Shaematobium & Shaematobium & ShF & Sh \\
\hline \multicolumn{5}{|l|}{ Patient 9} \\
\hline 1 miracidium & Shaematobium & Sbovis & $5 b 4$ & Hybrid \\
\hline 1 miracidium & Shaematobium & Sbovis & 565 & Hybrid \\
\hline 1 miracidium & Shaematobium & Sbovis & $\$ b 6$ & Hybrid \\
\hline 7 miracidia & Shoematobium & Shaematobium & ShD & $5 h$ \\
\hline \multicolumn{5}{|l|}{ Patient 105} \\
\hline 5 miracidia & Sharematobium & Sbovis & $5 b 2$ & Hybrid \\
\hline 1 miracidium & Shoematobium & Sbovis & $5 b 7$ & Hybrid \\
\hline \multicolumn{5}{|l|}{ Patient 115} \\
\hline 1 miracidium & Shaematobium & Shoematobium & ShD & Sh \\
\hline 6 miracidia & Shoematobium & Sbovis & $\mathrm{Sb} 2$ & Hybrid \\
\hline 1 miracidium & Shoematobium & Sbovis & 568 & Hybrid \\
\hline \multicolumn{5}{|l|}{ Patient 12} \\
\hline 5 miracidia & Shaematobium & Sbovis & $5 \mathrm{~b} 2$ & Hybrid \\
\hline
\end{tabular}

Numbers of eggs or miracidia are the number successfully profi led, rather than the number extracted. Of the 12 patients, patients 1-6 were tourists and 7-12 were Corsican locals. rDNA=ribosomal DNA.

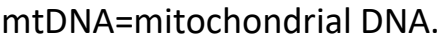

ITS=internal spacer region. $S$ haematobium=Schistosoma haematobium. $S$ bovis=Schistosoma bovis. $S$ $h=$ pure $S$ haematobium. $S b=$ pure $S$ bovis. Hybrid=S haematobium $-S$ bovis hybrids.

*The mtDNA cox1 haplotype codes for each genetic type.

tGenetic profile identifies the type of infection.

$¥$ Patients from the same family.

$\S$ Patients from the same family 
Table 2

cox1 polymorphic site mutations within the different Schistosoma haematobium haplotype sequences

\begin{tabular}{|c|c|c|c|c|c|c|c|c|c|c|c|}
\hline & \multirow{2}{*}{$\begin{array}{l}\text { Number of eggs } \\
\text { or miracidia }\end{array}$} & \multicolumn{10}{|c|}{ cox 1 sequence position mutations } \\
\hline & & 184 & 201 & 213 & 241 & 252 & 463 & 574 & 597 & 773 & 839 \\
\hline ShD & 15 & $\mathrm{c}$ & G & A & G & G & G & G & $T$ & G & G \\
\hline ShB & 8 & $\mathrm{~T}$ & $*$ & H & - & $n$ & A & $n$ & - & + & $n$ \\
\hline $\operatorname{Sh} A$ & 16 & $"$ & " & 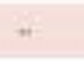 & $A$ & $\pi$ & 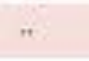 & A & $=$ & H & $"$ \\
\hline ShC & 1 & $T$ & A & * & m & " & A & \% & - & * & " \\
\hline ShE & 1 & $"$ & $*$ & H & $=$ & A & $\pi$ & + & - & A & A \\
\hline ShF & 1 & " & " & $m$ & $m$ & $m$ & $n$ & $\pi$ & $c$ & $m$ & $n$ \\
\hline
\end{tabular}


Table 3

cox1 polymorphic site mutations within the dif erent Schistosoma bovis haplotype sequences

\begin{tabular}{|c|c|c|c|c|c|c|c|c|c|c|c|c|c|}
\hline & \multirow{2}{*}{$\begin{array}{l}\text { Number of eggs } \\
\text { or miracidia }\end{array}$} & \multicolumn{12}{|c|}{ cox1 sequence position mutations } \\
\hline & & 147 & 199 & 207 & 358 & 474 & 623 & 626 & 633 & 758 & 773 & 787 & 811 \\
\hline $5 b 2$ & 24 & G & $T$ & G & G & G & G & G & C & G & G & G & G \\
\hline Sb1 & 1 & " & " & $=$ & 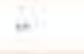 & - & -1 & $"$ & " & " & $"$ & $=$ & A \\
\hline $\mathrm{Sb}_{3}$ & 1 & r & $"$ & $=$ & + & + & $\omega$ & $"$ & $"$ & " & $n$ & A & 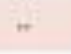 \\
\hline Sb4 & 1 & - & $c$ & A & $\pi$ & - & A & 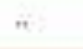 & $"$ & $\pi$ & $n$ & - & $r$ \\
\hline 565 & 1 & " & $"$ & H & H & - & + & A & " & $\%$ & " & - & $\mu$ \\
\hline $5 b 6$ & 1 & - & " & $=$ & $\pi$ & $=$ & $\pi$ & $n$ & $T$ & $\pi$ & $\pi$ & $=$ & " \\
\hline Sb7 & 1 & $m$ & " & $=$ & $n$ & 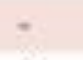 & $n$ & $n$ & " & A & A & $=$ & $n$ \\
\hline 568 & 1 & A & " & $=$ & A & A & H & $n$ & " & $n$ & 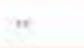 & $=$ & $\pi$ \\
\hline
\end{tabular}


Table 4

Experimental infection of Bulinus truncatus snails

\begin{tabular}{lllll} 
& $\begin{array}{l}\text { Number of } \\
\text { exposed } \\
\text { snails }\end{array}$ & $\begin{array}{l}\text { Number of } \\
\text { surviving } \\
\text { snails }\end{array}$ & $\begin{array}{l}\text { Number of } \\
\text { infected } \\
\text { snails }\end{array}$ & $\begin{array}{l}\text { Prevalence of } \\
\text { infection }\end{array}$ \\
\hline 1 miracidium & 24 & 18 & 3 & $17 \%$ \\
2 miracidia & 48 & 48 & 6 & $13 \%$ \\
3 miracidia & 35 & 34 & 8 & $24 \%$ \\
Infections performed on snails collected in the Cavu River with schistosomes \\
recovered from a single patient identified as patient 12 infection was confirmed \\
by matural cercarial emission at 48 days post exposure.
\end{tabular}

